\title{
AN INVESTIGATION INTO FACTORS INFLUENCING INTERNATIONAL STRATEGIC ALLIANCE PROCESS
}

\author{
Sari Wahyuni \\ Pervez N. Ghauri \\ Theo J.B.M. Postma
}

Empirical research indicates that strategic alliances, like other organisational forms, emerge as an adaptive mechanism to market uncertainty, and their developments over time reflect the co-evolution of distinctive firm capabilities and of industry and market activities. Interestingly: most strategic alliances go through similar coevolutionary cycles in terms of their motives and capabilities toward the cooperative relationship. Studies in this area show that alliance failure is an outcome of the coevolutionary adjustment to changes in the market, the competitive dynamics between partmers, and assessment of efficiency of the alliance as an alternative governance structure. It is thus critical to adopt a dynamics perspective and historical observations of cooperative process. This paper attempts to distil, derive and integrate theories across different perspectives into a unified framework that offers a better understanding of alliance process development. Our analysis shows that we can divide strategic alliance development into three phases of development: formation, operation and evaluation. We further endeavour to seek the important factors that should be taken into account in each stage of their life.

Keywords: cross-culture differences: important factors: life cycle: negotiation: stratcgic alliances: trust 


\section{Introduction}

The growing literature on strategic alliance suffers from imbalance. While the importance of evolutionary processes is well recognized in many sublields of management and organization theory (sce for instance Cameron et al. 1988; Baum and Singh 1994; Burgelman 1994; Teece et al. 1997), studies of strategic alliances as evolutionary processes are scarce. Most rescarchers have focused either on explaining pattern of alliance formation (c.g. Gabrielli 1986; Haklisch 1986: Pisano 1987: Tyebjce 1988: Doz 1992) or on relating alliance outcomes to initial characteristics of the alliance or of its partners. However, little is known about the managerial aspects (such as partner selection and coping with conflict) of the different life stages through which alliances pass. Integraling rescarch that tries to link the process development of strategic alliances 10 these managerial aspects has less been done. This article is devoled to bridge this gap.

In this paper, we sketch out the process development of strategic alliances (cspecially international oncs) and identify a sel of managerial aspects that should be laken into account in each phasc of the alliance development. Strategic alliances are here defined as agreements to cooperate between two or more firms, that are of strategic importance to their competitive viability (Mockler 1999). In giving a basic understanding on the process development of strategic alliance, this paper starts with an overview of the alliance life cycle literature. We believe that a study of the alliance development will not be complete without taking into consideration the life cycle and the development of their relationship. The life-cycle concept is helpful in dilferentiating phases of collahoration that arise during an alliance life span, from seeking a partner to terminating the alliance. Subsequently, literature on the strialegic alliance development will be considered and compared to the literature on alliance life cycle, alliance relationship and their strategy development. From this comparison, a framework of the strategic alliance process development will be proposed and discussed. This paper ends with a short conclusion.

\section{Research on the Process Development of Strategic Alliance}

In this section, we will start the discussion with the life cycle of alliances. Section "Development of an Alliance Relationship" goes into the literature on development of an alliance relationship. In Section "Studics on Strategic Alliance's Development" we discuss previous studies on strategic alliance's development. Finally, section "Summing up" offers a summing up of the literature review on strategic alliances.

\section{The Life Cycle of Strategic Alliance}

Alliances do not stand still, at lcast if they are to survive. As partnerships, often are formed in response to challenging $\mathrm{com}-$ petitive conditions, they are founded upon relationships that are dynamic of their own and are subject to the influence of external changes bearing not only directly upon the alliance but also on the partners separately. They have to transform and adapt with a sense of direction. For most alliances, however, the choice appears to be to evolve or to fail.

The evolution of alliances can proceed along different paths, which ulti- 
Wahrumi. Ghauri. Posmma -An Investigation into ...

Figure 1. A Life Cycle Model of Strategic Alliance

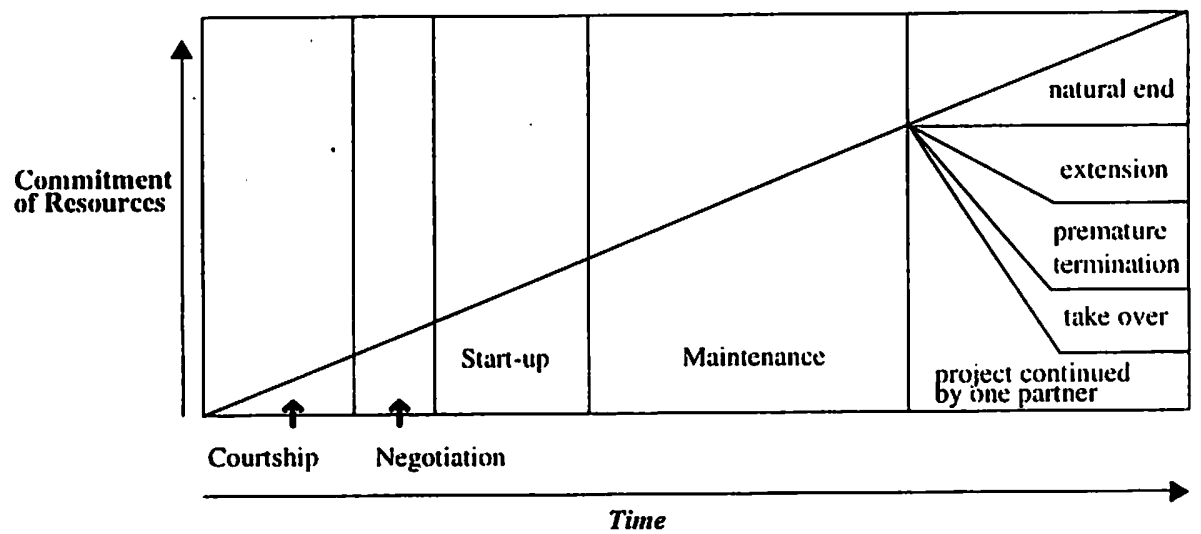

Source: Muray and Mahon (1993); Dussauge and Garrete (1998)

mately lead to the continuity or discontinuity of the cooperation. Experiences of joint ventures with US partners suggest that there are two critical periods in their existence (Bleeke and Ernst 1995). The first comes about two or three years after the start of the alliance, by which time any unsatisfactory relationship should have hecome evident. The second comes after about five or six years of alliance life, by that time one partner may be ready to move onto another arrangement. This could be disengagement from, continuity of the partnership or take over of the other partner. It has been estimated that the median life span for alliances is only about seven years and that nearly 80 percent of strategic alliances eventually end in a sale by onc of the partners. There is amplc.evidence for all these possible outcomes, and no one particular outcome is inevitable. Outcomes depend crucially upon the ongoing relationships between the partners and the changing strategic intent of the partners. Muray and Mahon (1993) depict alliances as exhibiting a life cycle as illustrated in Figure 1.
The two axes of Figure 1 indicalc time and commitment of resources by the alliance partners. Alliances begin with a courtship stage, as does any relationship. If this goes well, detailed negotiations follow to develop an agreement. Then they move up to stage three, the start-up phase in which joint activity begins, and substantial resources are commitled. Muray and Mahon describe the next stage as the maintenance phase, which involves the routine of operations and reporting relationships, as the organizations continue to work together on an operational basis. This is, of course, the phase in which the ultimate success of the alliance will he tested, as it gains in responsibilitics. continues in steady mode, or declines in importance and becomes marginalized by the partners. The fifth stage of the life cycle is described as the ending, which can take a number of forms:

1. the end of the specific relationship with extensions into other areas of mutual interest ;

2. an amicable separation with no immediate further joint activity; 
3. a hostile parting, inhibiting the likelihood of any future joint activity.

The time line for the fourth stage may, of coursc, be short or extended to an infinite length, depending on circumstances.

While Muray and Mahon (1993) suggest three possibilities of development, Dussauge and Garrette (1998) propose more options of development. They identify five major developments leading to reorganization or termination of an alliance with examples as follows:

1. The alliance comes to a "natural end" once the objectives for which it was created have been achieved. For example. Dassault and British Aerospace, which had jointly designed and manufactured the Jaguar fighter aircraft, terminated their alliance once the program was over and no more planes were being ordered.

2. The alliance is extended or expanded. The partner firms choose to prolong their collaboration over successive generations of the joint product or expand it to new products or projects. Thus, Renault and Matra collaborated on three successive generations of the Espace minivan, while the Airbus cooperation has been expanded to include a complete family of aeroplanes.

3. Premature termination. The partner firms break up the alliance before the initial goals have been achieved. MatraHarris and Intel, for example, broke up their Cimatel alliance in 1987, before any of the VLSI chips Cimatel meant to produce were actually manufactured.

4. One partner continues the joint project alone, while the other partner pulls out before any tangible results have been achieved. For example, Fairchild and Saab were designing a commuter air- craft (the SF-340) together when Fairchild, who was having problems of its own, decided to drop the projec which was continued by Saab (th project was renamed Saab 340).

5. Takeover of one partner firm by th other. The alliance comes to an en when the other acquires one of the a. lies. ICL, the British computer gian was taken over by Fujitsu in 1990, aft6, almost ten years of collaboration in th. area of mainfiame computers.'

Another study conducted by Buche: and Killing (2002) discerns three stages $c$ alliance life cycle. These are initial condi tions, executing conditions and evaluatin:conditions. According to them, alliance. develop through the initial conditions of commitment and negotiation with, ide. ally, all parties involved perceive that the are creating an efficient and equitable or ganizational form. Initial conditions ars: the outcome of the formation stage wher: the partners negotiate the agreement and these conditions have an important impac: on performance, leaving an imprint on the organization at birth by imparting a unique character which affects subsequent struc. ture and performance. Once the alliance is formed, the final agreement is translated into execution. As the ISA managers execute this agreement, change in either partner's environment may affect their strategy or organizational setup. This can lead to a situation of evaluation. In this situation, the initial agreement is reassessed as a result of an imbalance in the partners' perception of value generated from the ISA. When this occurs, the alfected partners attempt to restore this imbalance by adjusting their contribution to the ISA and thereby restoring equity in the relationship. The important variables in these three stages are described in Table 1.

\footnotetext{
'All examples on these trends of development are taken from Dussauge and Garrelle (1998).
} 
Table 1. Strategic Alliance Development: Comparison of Different Perspectives

\begin{tabular}{|c|c|c|c|c|}
\hline $\begin{array}{l}\text { Area of } \\
\text { Interest }\end{array}$ & Stages & Characteristic on Each Stage & Authors & $\begin{array}{c}\text { Exchange of Relevant } \\
\text { Literature }\end{array}$ \\
\hline \multirow[t]{2}{*}{$\begin{array}{l}\text { Life Cycle } \\
\text { of alliances }\end{array}$} & $\begin{array}{l}\text { 1. Courtship } \\
\text { 2. Negotiation } \\
\text { 3. Start-up } \\
\text { 4. Maintenance } \\
\text { 5. Evolution }\end{array}$ & $\begin{array}{l}\text { Only the development of relationship explanation. no lurther information } \\
\text { on important elements in each stages. The alliances will evolute on five types of } \\
\text { relationship: natural ends. extension, take over by one partner. preinature } \\
\text { termination. project continued by one parner. }\end{array}$ & $\begin{array}{l}\text { Muray and } \\
\text { Mahon (1993) }\end{array}$ & $\begin{array}{l}\text { Dussauge and Garrelte (1998); } \\
\text { Ring and Van de Ven (1994). }\end{array}$ \\
\hline & $\begin{array}{l}\text { 1. *) Initial conditions } \\
\text { <imprinting } \\
\text { 2. Executing conditions } \\
\text { 3. Evaluating conditions }\end{array}$ & $\begin{array}{l}\text { I. *) Initial relational quality. initial employee involvement. initial staffing } \\
\text { 2. Ongoing investment into relational quality. conflict-resolution mechanism. } \\
\text { extensive information exchange. strong partner interfaces. } \\
\text { 3. Equity (economic calculation and social indebtedness) }\end{array}$ & $\begin{array}{l}\text { Buchel and } \\
\text { Killing (2002) }\end{array}$ & $\begin{array}{l}\text { Buchel (2000): Arino and } \\
\text { dela Torre (1998): Ring and } \\
\text { van de Ven (1994). } \\
\quad \text {. }\end{array}$ \\
\hline \multirow[t]{2}{*}{$\begin{array}{l}\text { Development } \\
\text { of relationship }\end{array}$} & $\begin{array}{l}\text { 1. Anticipation } \\
\text { 2. Engagement } \\
\text { 3. Valuation } \\
\text { 4. Coordination } \\
\text { 5. Investment } \\
\text { 6. Stabilization } \\
\text { 7. Decision }\end{array}$ & $\begin{array}{l}\text { 1. Pre-alliance. competitive need and motivation emerge } \rightarrow \text { partner search } \\
\text { 2. High energy. complementarily. strategic potential } \rightarrow \text { partner identification } \\
\text { 3. Financial focus. business } \\
\text { 4. Operational focus. task orientation } \rightarrow \text { coordination interfacing } \\
\text { 5. Commitment. resource reallocation. broadening scope } \rightarrow \text { expansion growth } \\
\text { 6. High interdependence. assessment of relative worth and contribution } \\
\rightarrow \text { adjustment } \\
\text { 7. Where now? } \rightarrow \text { reevaluation }\end{array}$ & $\begin{array}{l}\text { Spekman et al. } \\
\text { (1998) }\end{array}$ & $\begin{array}{l}\text { Dweyer et al. (1987): } \\
\text { Muray and Mahon (1993) }\end{array}$ \\
\hline & $\begin{array}{l}\text { 1. Alliance formation } \\
\text { 2. Alliance create value } \\
\text { 3. Interorganization dynamic }\end{array}$ & $\begin{array}{l}\text { 1. Trust. commitment. recognized interdependence. level of communication. } \\
\text { strategic alliances. partner selection. relationship configuration and alliance } \\
\text { implementation. negotiating the legal and contractual parameter. equity issue } \\
\text { 2. Permit partners to talk with a "louder voice" and quickly grow market share. } \\
\text { develop synergy. problem arise when expectation differ } \\
\text { 3. High-level of efficiency and profitability. control (formal and informal). Irust. } \\
\text { development of informal network and information }\end{array}$ & $\begin{array}{l}\text { Spekman.et al. } \\
\text { (1998) }\end{array}$ & $\begin{array}{l}\text { Larson (1992) } \\
\text { Lei and Slocum (1991) }\end{array}$ \\
\hline
\end{tabular}




\begin{tabular}{|c|c|c|c|c|}
\hline $\begin{array}{l}\text { Area of } \\
\text { Interest }\end{array}$ & Stages & Characteristic on Each Stage & Authors & $\begin{array}{l}\text { Exchange of Relevant } \\
\text { Lifterature }\end{array}$ \\
\hline & $\begin{array}{l}\text { I. Formation } \\
\text { 2. Operation } \\
\text { 3. Outcome }\end{array}$ & $\begin{array}{l}\text { 1. High level of collective strength. low level of inter-partner conflict. high level } \\
\text { of interdependencies } \\
\text { 2. Two possibilities: negative development (collective strength will downturn. } \\
\text { the increasing opportunistic behavior. conflict increases) and positive } \\
\text { ( interdependencies will go down. increase collective strength. conflict } \\
\text { decreases) } \\
\text { 3. Four possible outcomes: stabilization. reformation. decline. termination }\end{array}$ & $\begin{array}{l}\text { Das and } \\
\text { Teng (2002) }\end{array}$ & $\begin{array}{l}\text { Ring and Van de Ven (1994) } \\
\text { Das and Rahman (2002) }\end{array}$ \\
\hline \multirow[t]{3}{*}{$\begin{array}{l}\text { Strategic } \\
\text { Alliance } \\
\text { Development }\end{array}$} & $\begin{array}{l}\text { 1. Formation } \\
\text { 2. Management } \\
\text { 3. Evolution }\end{array}$ & $\begin{array}{l}\text { 1. Form of alliances. motivation. partner selection } \\
\text { 2. Managing conflict. cross culture differences. commitment and trust. } \\
\text { system information } \\
\text { 3. Perception of balance benefit. development of strong bonding power. } \\
\text { development of new project. organizational learning }\end{array}$ & Faulkner (1995) & $\begin{array}{l}\text { Lorange and Roos (1992) } \\
\text { Das and Teng (2002). }\end{array}$ \\
\hline & $\begin{array}{l}\text { 1. Formation } \\
\text { 2. Adjustmen! } \\
\text { 3. Evaluation }\end{array}$ & $\begin{array}{l}\text { I. Informal (internal negotiation and stakeholder blessing) and formal phase } \\
\text { (negotiation with partner. internal support and establishment of personnel } \\
\text { relationship) } \\
\text { 2. How to fulfil the objective of their cooperalion. the process socialization. } \\
\text { the adaptation of the changes in the environnent. and the exchange process } \\
\text { between the partners and the joint venture } \\
\text { 3. The evaluation process and decisions for the fiture cooperation. }\end{array}$ & $\begin{array}{l}\text { Buchel et al. } \\
\text { (1998) }\end{array}$ & Lorange and Roos (1991) \\
\hline & $\begin{array}{l}\text { 1. The nature of cooperalion } \\
\text { 2. Establishing cooperation } \\
\text { 3. Managing cooperation } \\
\text { 4. Maluring Relationship }\end{array}$ & $\begin{array}{l}\text { 1. Different perspectives. Irust, motives } \\
\text { 2. Partner and form selection. network and virtuality. negotiation and valuation } \\
\text { 3. General management. control. human resources management. culture. } \\
\text { emerging economies } \\
\text { 4. Organizational learning. the evolving alliance }\end{array}$ & $\begin{array}{l}\text { Child and } \\
\text { Faulkner (1998) }\end{array}$ & Berquisl el al.(1995) \\
\hline
\end{tabular}


Continued from Table I

\begin{tabular}{|c|c|c|c|c|}
\hline $\begin{array}{l}\text { Area of } \\
\text { Interest }\end{array}$ & Stages & Characteristic on Each Stage & Authors & $\begin{array}{c}\text { Exchange of Relevant } \\
\text { Literature }\end{array}$ \\
\hline \multirow[t]{4}{*}{ Sirategy } & $\begin{array}{l}\text { I. Learning } \\
\text { 2. Reevaluation } \\
\text { 3. Readjustment }\end{array}$ & $\begin{array}{l}\text { 1. Environment. lask. process. skills. goals } \\
\text { 2. Efficiency. equity. adaptability } \\
\text { 3. Task definition. partners routines. interface structure. expectation of: } \\
\text { performance. behavior. motives }\end{array}$ & $\operatorname{Doz}(1996)$ & Pitts and Lei (1997) \\
\hline & $\begin{array}{l}\text { 1. Courtship and Commitment } \\
\text { 2. Day to day relationship } \\
\text { 3. Transformation }\end{array}$ & $\begin{array}{l}\text { 1. Motives. partner selection. dangers of whirlwind courtship } \\
\text { 2. Managing relationship and conflict: respect difference opinion. open } \\
\text { communication. shared vision. } \\
\text { partnership maintenance: maintaining trust. differentiation and integration of } \\
\text { function. enjoyment of the work. } \\
\text { 3. In sickness and health; changing in partnership status. internal environment. } \\
\text { external needs and sources. market place. terminating a parnership. short-term } \\
\text { partnership. end of partnership }\end{array}$ & $\begin{array}{l}\text { Berquist. el al. } \\
\text { (1995) }\end{array}$ & Arino and de la Torre (1998) \\
\hline & $\begin{array}{l}\text { 1. Identification } \\
\text { 2. Valuation } \\
\text { 3. Negntiation } \\
\text { 4. Implementation }\end{array}$ & $\begin{array}{l}\text { 1. Define strategy and objective. screening for partners } \\
\text { 2. Assessing tradable and leverage. defining opportunity. assessing impact on } \\
\text { stakeholders } \\
\text { 3. Assessing bargaining power. planning integration } \\
\text { 4. Planning integration. implementing }\end{array}$ & $\begin{array}{l}\text { Hasbinson and } \\
\text { Pekar (1998a) }\end{array}$ & Bell and Bocrsma (2000) \\
\hline & $\begin{array}{l}\text { 1. Rethinking the business } \\
\text { 2. Crafting an alliance strategy } \\
\text { 3. Structuring alliances } \\
\text { 4. Evaluating alliances }\end{array}$ & $\begin{array}{l}\text { 1. Strategic reassessment. establishing a role for alliances } \\
\text { 2. Evaluating each firms value activities. distributing value chain activities. } \\
\text { leveraging in-house and partners resources. creating fall-back positions. } \\
\text { maintaining strategic options } \\
\text { 3. Importance of structures. framework for structures. key considerations. role } \\
\text { of bargaining } \\
\text { 4. Assessing alliances. learning about alliances. rethinking the alliance strategy. }\end{array}$ & $\begin{array}{l}\text { Yoshino and } \\
\text { Rangan (1995) }\end{array}$ & Bruce and Steve (1994) \\
\hline
\end{tabular}

*) The same number between these two columns represents the important lactors that need to be laken into account in each stive of an alliance life. 


\section{Development of an Alliance Relationship}

The wide acceptance of the life cycle approach also stimulated some rescarchers to explore the phases through which the relationships emerge, grow and dissolve (c.g. Dwyer et al. 1987; Larson 1992ab; Murray and Mahon 1993; Ring and Van de Ven 1992). An interesting life cycle alliance study done by Spekman et al. (1998) shows that there are seven subsequent main managerial activities:

1. Anticipating is the preliminary activity in which the organization envisions the possibilities, ideas and dreams of alliances. Managers begin to articulate a strategic intent for the alliance and requisite critcria for potential partner.

2. Engaging follows and the partners begin to shape their mutual expectation and steering committees are formed. Here begins the process of converting the drcam into reality.

3. Valuing is the period when the business exchanges are finalized. Partners bring in both skills and resources and each attempt to measure the relative worth of these assets.

4. Coordinating describes the activity in which a more permanent governance structure begins to emerge and integration/coordination becomes a focus.

5. Investing captures the hard realities of the alliance in which partners must "invest" (i.c. commit) in the future course of the alliance. Assets are formally committed and resources are dedicated to the alliance's mission.

6. Stabilizing is the activity, which indicates that the alliance is mature and realizes its potential. In this stage, performance is measured against objectives, financial targets and operational milestones rather than less tangible measures.

Each activity is built on a changing alliance landscape as the vision becomes reality and then grows into a mature business. Each activity is presented as a discretc event although, in reality, such boundaries are not so clcar. It is hard, for instance, to mark with precision where one activity begins and the other one ends. The activities proposed by Spekman et al. (1998) are intended to reflect key activities that account for dilferences in managerial behavior and which are thought to apply to alliance management.

However, it should also be realized that simply enumerating a set of activitics might not be equivalent to the full impact of examining an alliance through the lens of the life cycle perspective. There is also a dynamic interplay of activitics, people and processes. Furthermore, the research carried out by Spekman et al. (1998) also shows that the development of relationship in an alliance could be sketched out in three stages: the alliance formation, creation of value and inter-organizational dynamics.

The studies of Spekınan et al. (1998) and Muray and Mahon (1993) indicale that a critical path of alliance life cycle normally arises in their mid-life. Figure 1 shows that if firms can manage successfully their alliance relationship during the maintenance stage, they will go further and extend their relationship. Conversely, if they failed in managing this stage, they will end up with the discontinuity of cooperation. The same holds for the valuation and coordination stages proposed by S̀pckman et al. (1998).

A similar analysis is forwarded by Das and Rahman (2002) who propose three generic stages: formation, operation and 
outcome. They emphasize the possibility of opportunistic behavior. In the formation stage, prospective members focus on the preparation for establishing the alliance. A firm has to select partners and conducl extensive negotiation beforc finalizing a partnership agreement. There is both formal deal making and informal relationship building in this first stage of the alliance. Neverthcless, the potential for a partner's opportunism would always mitigate alliance formation in varying degrees. because firms need to have a certain minimum level of confidence in their partners to forge an alliance. Depending on the lirm's perception of potential opportunislic behavior by the partner, certain substantive deterrence mechanisms can be instituled. Preventive mechanisms in the formation stage include contractual provision and resource commitment.

According to Das and Rahman (2002), a stratcgic alliance comes to life in the operation stage as members collaborate to achieve alliance objective. Arguably, the operation stage is the most critical in alliance development. The nature of interdependence, which initially triggers the memher firms to forge the alliance. often changes during this stage, tending potentially towards alliance instability (Das and Teng 2002). In the operation stage the focal lirm would strive to detect signs of partner opportunism so that it could have time to protect itself from adverse consequences. Operational mechanisms are needed to shield the focal firm from such opportunism during this action-oriented stage of alliance development. Deterrence mechanisms in the operation stage include monitoring and participatory decisionmaking.

When collaboration efforts are implemented to accomplish the alliance objectives, the results are produced in the final phase or the outcome stage. Alliance members evaluate the actual result and depending on their assessment, either reform or terminate the alliance (Das and Rahman 2002). Opportunistic behavior in the outcome stage will pose a threat only when preventive and operational mechanisms have failed.

\section{Studies on Strategic Alliance's Development}

The previous discussion centered on the life cycle approach and how the relationship is developed. In this section, the literature on the process development of alliances is sketched out. There are various findings that share almost the sime approach towards strategic alliance de velopment (see e.g. Lorange and Roos 1'192; Faulkner 1995; Buchel el al. 1998; Child and Faulkner 1998).

Lorange and Roos (1992) propcise a generic model for an ISA's developnient, which consists of formation, implementation, and evolution. This model is base $\mathrm{t}$ on their assumption that strategic alliances are relatively similar with an organic entity that grows and develops in nature. Like the birth and growth of a child until it becomes an adult, when the influenc: of the parents become less dominant and it is ready to be an independent entity. This type of development normally happen $:$ in joint venture cooperation. A success ful joint venture commences with respor sibilities firmly in both partners' hands,, !eveloping into a situation in which the $v i n$ ture claims more responsibilities for its' If. At this stage, one partner may becom: a freestanding entity with its own indepc ndent management. In strategic alliancis. the hands-on coordination between two parties may lead to a natural search by a partner to gradually "extradite" itself by 
Iransferring more and more functions to the alliance itsclf. It commonly happens that one partner becomes more important and the other is relegated to secondary status. This condition could be stressful for both partners. As a result, there is a great number of alliances. which are terminated after a period of time if partners cannol adapt to the new conditions of their cooperation. Therefore, a careful future plan and liexible adaptation to the various possible cvolutions need to be prepared for even at the beginning of their partnership.

Whereas Lorange and Roos (1992) stress the process of alliance development, Faulkner (1995) proposes a more detailed framework by trying to sketch out the important aspects in each phase of the alliance process. He distinguishes alliance devclopment in three phases: alliance formation. management and evolution. The formation of an alliance is one of the first issues to be addressed, once the prospeclive partners have agreed to embark upon a collaborative agreement. It consists of the selection of an alliance form, the motivation of an alliance, and partner selection. After this formation phasc, the question arises: "what is the best way to manage the alliance?" Faulkner (1995) labeled this second step as the management phase. The important lactors that should be considered in this stage are control, dispute resolution mechanjsm, clarity of authority, divorce procedure, information dissemination. congruent goals and positive partners' attitude (mutual trust, commitment and cultural sensitivity). The last phase is cvolution. Faulkner indicates the relative importance of the various significant evolution variables by establishing new projects such as flexible adjustment, balanced development, partner bonding, and organizational learning.
Based on a study of joint ventures. Buchel et al. (1998) identify three phases of development, namely, formation, adjustment and evaluation. In the formation phase, the relationship between the partners is of central importance because this is the phase in which they work together to decide the future form of the joint venture. This phase has been split up into two subphases: the informal (internal negotiation and stakeholder blessing) and the formal phase (negotiation with partner, internal support and establishment of personnel relationships). In the adjustment phase. the emphasis is on the way to fulfill the objective of their cooperation, the socialization process, adaptation to the changes in the environment, and the exchange processes between the partners and the joint venture itself as an independent entity. In the evaluation phase, the whole joint venture system is assessed. This includes the evaluation of whether they have achieved their objectives, and decisions for future cooperation.

Child and Faulkner (1998) identify more detailed phases and relevant factors in each phase of an alliance life. According to them, there are four phases in alliance development: nature of cooperation, establishing cooperation, managing cooperation, and maturing relationship. The nature of cooperation is the foundation for the beginning of an alliance relationship, which is colored by the different perspectives, trust and motivation of parties. In the second step, alliance strategies are concerned with how cooperation between firms is established and the various forms it can take. It consists of partner and form selection, networks and virtuality, negotiation and valuation. The third phase consists of the overall management of strategic alliances. The management of stratcgic alliances differs in its essential nature 
compared 10 integrated companics. The ahility $t o$ give instructions is replaced by the need to seek areas of mutual agreement and to develop constituencies behind a course of action (Kanter 1989). Control, management of human resources and cultural problems are also important factors in this phase. The last phase, the maturing relationship. deals with what is perhaps ultimately the most important factor in the creation of a lasting mutually beneficial cooperative arrangement between companies - namely. how to stimulate the relationship to crolve and mature, and how to ensure that organizational learning remains its primary purpose. Thus, organization learning and the development of cooperation are ultimately the concerns of every cooperation.

Another study conducted by Doz. (1996) explores the development of cooperation in alliances between firms, and in particular how this development is constrained by the conditions at the inception of the alliance and influenced by the collaboration that takes place subsequently. He developed a framework of alliance development that reveals patterns of interactions between initial conditions, learning processes, reevaluation and adjustment on the part of the alliance partners and outcomes. Initial conditions (set in terms of task definition, partners' organizational routines. interface structure and partners' expectation) facilitate or hamper partner learning along five dimensions: environment, task, process, skills and goals. Learning, in turn, allows the partner to recvaluate their partnership on the basis of perceived efficiency, equity and adaptability. Reevaluation then lcads to readjustment of initial conditions, and hopefully, to a new cycle of learning and reevaluation. Partners in more successful alliances arc engaged in such a series of iterative and interactive learning cycles over time. typically characterized by increasing trust and adaptive flexibility, as well as the willingness to make larger and larger, as well as increasingly specific and irreversible. commitments.

Doz's(1996) study indicates that therc are four driving factors in an alliance development. First, the two partners enter their relationship with a definition of the task to be performed. In this phase, each partner has a mutual understanding of their expectation of performance, behavior and motives. Second, each partner projects onto the other, through the interface in their alliance, a set of organizational action routines borrowed from its owned organizational context, that becomes baftling, disconcerting and ultimately aggravating to members of the partner lirm. In particular. while the "top" and "bottom" cooperate. the middle management ranks are not (sulficiently) involved. This increases counterproductive behavior such as jealousy and a hierarchical organization. Third, the interface between the two partners is initially "light" and does not allow for the recognition and the appreciation of differences between the ways the two firms operate. During the development of the relation, the interface hecomes more substantive and leads to share understanding. Doz. proposes three determinant factors in this respect that are the definition of the task to be jointly performed, the partner's respective organizational routines. and the interface between them. The fourth factor plays a rather obvious role: expectation. Each partner has its own expectation, which leads to its strategies in entering the alliance form. Therefore. managers need to know what kind of action should be taken in each phase of development. 
Harbinson and Pekar (1998a) compiled a management practice guide in four phases of alliance formation -identificalion. valuation, negotiation, and implementation - and break them down into eight practically and actionable steps. They discuss what occurs in each step of alliance formation and the kinds of best practices cach step typically calls for. Yoshino and Rangan (1995) stress strategy in each phase of alliance development. They discern three key lcssons to be learned:

1. Only after its overall strategy is set can a firm decide what types of alliances to engage in and what role they will play in the broader corporate strategy. Having decided to forge an alliance, a firm must consider its choice of partners and manner of negotiating, undertake the often complex and time-consuming task of structuring the alliance, and commit adequate talent and resources to its ongoing management.

2. It refers to the manner in which alliances are forged, structured and managed over time and how it impinges on the conception, and, if necessary, a revision of a company's overall strategy itself. This is as it should be. Strategy is not lashion design, intended to change recurrently. As an alliance progresses, it invariably influences a firm's choice of future strategies.

3. The ultimatc lesson of alliances concorns managing both the strategic development and the changing role of alliances. That is to say, managers must not only worry about the effects of their alliance on their strategies and the changing role of different types of alliances employed in particular strategies, but also ensure that changes in strategies and the role of the alliances occur in tandem. As a network of alliances develops, this becomes an exacting lask that if not executed effectively can spell disaster for a firm.

Yoshino and Rangan (1995: 42) also formulate lour stages of alliance strategy: rethinking the business, crafting an alliance strategy, structuring, and evaluating alliances (the detailed strategic actions is described in Table I).

\section{Summing $U p$}

In this section, we sketched the process development of strategic alliances from the perspective of its life cycle, the development of their relationships, the general development of strategic alliances, and the strategies needed throughout an alliance life. Even though each perspective analyzes those developments from a different point of view, we can see that there is a striking similarity with one another. All of them portray the sequential devclopment of strategic alliances from an initial phase, to a development phase, till alliance maturity. The process development of alliances is not sequential and linear, but rather iterative and circular.

Our research literature in this section also showed the same evidence that after the alliance formation, firms often face a difficult time in their cooperation. A characteristic question that arises in this phase is about the best way to manage their alliance. In this operational phase, people experience working on a daily basis with their alliance partner, in which many differences might become manifest (both in culturc, organization. behavior, etc.). They need to cope with conflict that might appear during their partnership, the commitment to the alliance, the exchange process with the partners and also the changes in the environment and strategy. This midlife phase of the alliance could be consi.:cred critical to further alliance development. This phase is so fragile that it deter- 
mines the continuity and discontinuity of the alliance. If the involved managers successfully manage this phase, they can conlinue their partnership but if they cannot manage it properly then a divorce or an ending of cooperation might be the best option they might take. Findings discussed in this section are summarized in Table 1.

\section{The Framework of an Alliance Development}

Based on the literature review in the previous section, we can draw the conclusion that the process development of strategic alliances can be divided into three main phases: formation. operation and evaluation. Figure 2 illustrates our framework in the process development of strate- gic alliances. Each phase is built on a changing alliance landscape as the vision becomes reality and the alliance grows into a mature relationship. Each phase is presented as a discrete event although, in reality, such boundaries are not so clear. It is hard, for instance, to mark with precision where one phase begins and where the other ends. Clearly phases 2 (operation) and 3 (evaluation) overlap in time, as phase 3 emerges from phase 2 .

We can see from Figure 2 that there is a line that goes back from the evaluation phase to the operational phase. It means that if both partners decide to continue their relationship after the evaluation phase, then the strategic alliances will encounter the variables in the operational phase. which might have a different nature from

Figure 2. Framework of Strategic Alliance Development

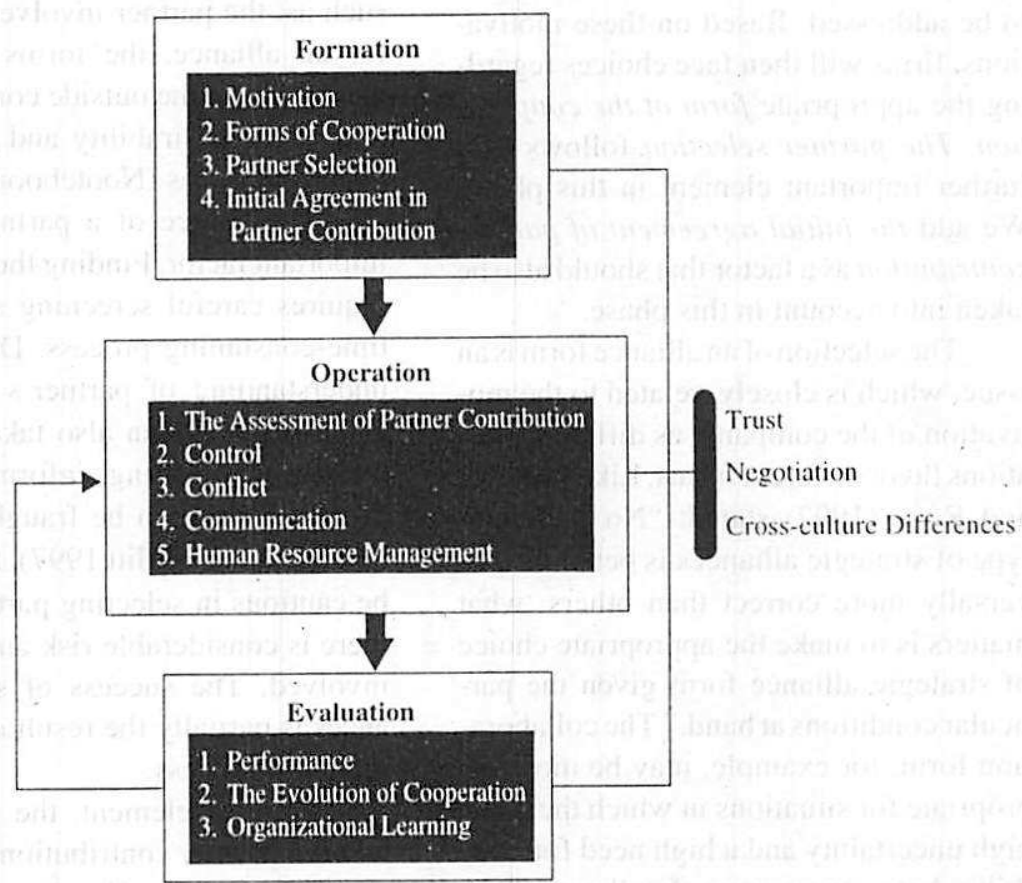

Based on: Faulkner (1995); Child and Faulkner (1998); Bichel et al. (1998); Parkhe (1996) 
the previous cooperation. It all depends on the type of the new cooperation, partner ohjective and strategic change of both paltners where their future is concerned.

Our litcrature review also indicates that there are three elements, which cannot put specifically in one of these three phases, namely: trust, negotiation and cross-culture differences. These three factors are significant and should be kept in mind during the whole process of strategic alliance development. The various elements of the framework will be discussed below.

\section{Formation Phase}

Alliances are formed for a wide variety of reasons. The different structural siluations require the preferred use of different forms of alliances. Thereforc, the recognition of motives in establishing strategic alliances is the first issue that needs to be addressed. Based on these molivations, firms will then face choices regarding the appropriate form of the cooperation. The partner selection follows as a further important element in this phase. We add the initial agreement of partner contribution as a factor that should also be laken into account in this phase.

The selection of an alliance form is an issue, which is closely, related to the motivation of the company, as different situations favor diflicrent forms. Like Lorange and Roos (1992) stated: "No particular type of strategic alliances is hetter or universally more correct than others; what malters is to make the appropriate choice of strategic alliance form given the particular conditions at hand." The collaboration form, for example, may be most appropriate for situations in which there is a high uncertainty and a high need for flexibility between partners (Faulkner 1995). Joint ventures are often formed where the alliance covers a distinct business area, generally not the core area of the companics, where the assets are distinct and separable from the partners feel the need to be committed to each other (Gupta and Singh 1991). On the other hand, consortia may be formed where the task is too large to be undertaken by only two companies from the level of financial commitment required to the variety of skills and competencies and, perhaps credibility with major clients, especially governments. However, most defence and aerospace enterprises and other industries requiring very high levels of research and development (R\&D) have these characteristics, and the consortium form is most frequently met in these sectors (Collins and Doorlcy 1991: Lei and Slocum 1991; Dussauge and Garrette 1998,2000). Finally, multiple causes should be taken into account in deciding a proper form of cooperation, such as: the partner involved, their goals for an alliance, the forms and designs available and the outside condition which affects the desirability and leasibility of goals and forms (Nooteboom 1999).

The choice of a partner is also an important factor. Finding the right partner requires careful screening and can be a time-consuning process. Developing an understanding of partner's expectations and objectives can also take time. In an international setting, informal brokering of an alliance can be fraught with problems (Dacin and Hitt 1997). Firms need to be cautious in selecting partners because there is considerable risk and investment involved. The success of stratcgic alliances is partially the result of the partner selection process.

The last element, the initial agreement in partner contribution, is related to the difficult issue of how to place value on partner's initial contribution to the alliance. Presently. there are not many re- 
searchers that suggest a specific partner contribution valuation in this phase. Due to the importance that inter ally with the difficulty of this assessment, it is, howcver, necessary for a company to make a clear distinction of each partner's contrihution in the beginning of their cooperation. Child and Faulkner (1998) note that it is far more difficult to calculate the value of a partner in a strategic alliance than in an acquisition. In an acquisition. after all, the market will decide the ultimate price in most cases, and opportunities, will he aflorded lor other bidders to enter the process. This is far less the case in strategic alliances, as most alliances are largely outside the view of the market, as a result of confidential negotiations carried out over a period of time. The form of the alliance also affects the valuation. If no joint venture company is formed, it is, for example, very difficult to determine where the boundaries of the alliance start and stop. Thus, the assessinent of a partner's value to the alliance will depend on an estimation of its present and future likely contribution (e.g. net present value), and will vary in its measurability on the choice of alliance form and the nature of the asset involved. It is also important to take a note that the initial agreement is frequently based on the mutual benefits that each company is likely to realize from the union of efforts. As the time progress, one party may find that it no longer needs the skills that are duplicable. Therefore, this partner contribution needs to be assessed further in the second phase of the alliance development.

\section{Operation Phase}

The interesting issue that arises in this stage is the paradox that to gain from an alliance, a partner needs to establish the ability to appropriate a substantial propor- tion of the value created by the alliance in the form of the successful internalization of new core competencies learned from the partner. However the more successfully the firm can do this. the less it appcars to need its partner and, hence, the bonds of the alliance become weaker (Child and Faulkner 1998).

Fortunately for the inherent value of alliances, like all good paradoxes, this is only an apparent contradiction and it arises from too static a view of an alliance. It assumes a finite set of competencies and skills, and that appropriation of value by one partner diminishes the pool available for the future. In fact it is likely that a successful alliance will, at the very least. produce value for the partner companics in the form of organizational learning. and also, at least in joint venture alliances. retain further value within the venture itself.

A strategic alliance is formed for the long term to achieve strategic objectives. For this, a management system needs to be established and operationalized efficiently. Harrigan (see Faulkner 1995), one of the most voluminous writers on joint ventures comments: "Alliances lail because operating managers do not make them work. not because the contracts are poorly written." Analyses of how strategic alliances are managed indicate that they should be managed as hybrid organizations in which all companies cooperatc to share investment, costs and risk, but remain independent with different motivations and objectives (Borys and Jemison 1989). Faulkner (1995) addresses some important factors that need to be pointed out during the management stage of strategic alliances:

- managing the conflict. This includes a good dispute resolution mechanism. and also a procedure to cater for possibilities that the alliance may cease to meet the expectations of the parties. 
- the establishment of systems to disseminate information throughout the company. In the absence of such systems there is a high risk that vital information, especially "know how," will remain with the partner and merely be used but not absorbed, or that it will go no further than the executives directly interfacing with their alliance partners and that it not becomes embedded in the partner companies tacit knowledge fabric.

- managing cross culture differences to smooth the way for harmonious working relationships. As many strategic alliances are built in the international area, there is a need to understand the cross culture differences of our parties.

managing commitment and trust. These relationships should provide a mechanism to limit opportunism. The more organizational complex an alliance is, the more it demands trust and commitment.

The last two factors, cross culture differences, commitment and trust, are so essential and should be kept in mind and applied properly throughout the whole life of alliances. Therefore, we discuss it separately from this stage.

In addition, few researchers consider human resource management (HRM) as an important item on the agenda in this phase (Child and Faulkner 1998; Yoshino and Rangan 1995). A carefully considered set of HRM policies and practices can make signilicant contributions to the success of strategic alliances. In the case of strategic alliances, the situation is further complicated by the presence of different national cultures and practices conditioned by different home-country institutions. Each party of an alliance normally brings to their cooperation their own cultures and associated HRM practices. A proper HRM plan can assist the adjustment of control promote organizational learning, and foster the selection and devclopment of staff who are capable of working effectivcly in a milieu of interorganizational collaboration. In these and other ways, HRM can help to enhance the productivity of alliances, as well as the ability of partners $t o$ benefit from them.

\section{Evaluation Phase}

Central to this phase is the evaluation process and its consequences. This consists of the alliance performance, alliance evolution and the organizational learning partner's derive from their cooperation. As an outcome of the alliance process, there is a need to know about the overall performance. Measurement of performance is important because partners have certain expectations. Strategic allianccs often operate in highly uncertain, risky settings and are used for purposes, which may result in ambiguous and sometimes even conflicting goals of the partners. This may imply that different partners have different performance criteria (Hyder 1988), especially if partners have different expectations about their alliance. It becomes apparent that performance measurement is a complex and controversial topic even at the individual firm level.

Still, scholars have grappled with performance measurement issues, often using "objective measures". Objective measures include financial indicators, market share, alliance survival and alliance duration. The main advantage of this type of measurement is its ability to provide reliable information regarding the extent to which the alliance has achievei its overall objectives (Geringer and Hebert 1991). This includes the financial performance, the achievement of goals such as technology transfer, organizational learn- 
ing and equitable division of rewards. Some authors indicate 'satisfaction' as an indicalor in this respect (see for example Beamish 1984: Geringer and Hebert 1991: Lee and Beamish 1995; Inkpen and Birkenshaw 1994). Satisfaction provides an indication ol the effectiveness and quality of the day-to-day interaction between the partners.

The ability to learn is probably the most intangible asset that a company can possess. The transfer of knowledge is a frequent and important motive for entering into a collaborative strategy. The process has come to be known as the "grafting" of new associates whom possess knowledge not previously available within the organization. The underlying attitude behind organizational learning of alliances can be collaborative or competitive. Collaborative learning allows for joint learning by both partners and is likely to be more productive over the long run. On the other hand, competitive learning creates a situation in which each partncr intends to learn as much as possible from the other, while at the same time offering as little knowledge as possible (to prevent spill(over). Organizational learning becomes a political foothall in the competitive process between lirms and this is not a sustainable situation in the long run (Child and Faulkner 1998). If this situation endures, the termination of the cooperation might be the hest option in the end. Thereforc. it is not surprisingly that the alliance performance evaluation and the organization learning they get from an alliance partnership have a great influence on the decision making process for the future cooperation.

The last aspect of an alliance is the evolution of their cooperation. The managcment may start loosing their interest as nothing-new results. To be continued thus an alliance needs to continuously develop and realize synergies. In other cases an alliance may, over time and through continuous evolution, develop a structure of its own, this is even more evident in the joint venture form of an alliance. Evolution is about continued value creation, which will, in successful collaboration alliance, be appropriated by the partners in a balanced fashion. Some value will emerge in terms of increased profits for shareholders, or for future investments, and some will emerge in the form of increased core competencies. Faulkner (1995) proposes the following conditions for evolution:

- perception of balanced benefits from the alliance by both partners,

the development of strong bonding factors.

- the regular development of new projects and responsibilities between partners.

- the adoption of a philosophy of constant learning by the partners.

Some studies (Lorange and Probst 1987; Nonaka 1989) emphasize that many alliance failures are due to the fact that they have not had sufficient adaptive properties built into them to cope with evolutionary pressure. Therefore, it is essential to understand the various types of strategic initiation situation as well as the potential evolutionary partners that might lie ahead. By understanding where one starts and what the evolutionary options and pressures are likely to be, one can be better prepared to allow the evolution to be a harmonious one.

\section{Trust, Negotiation and Cross Culture Differences}

Some researchers (e.g. Spekman et al. 1998; Faulkner 1995; Child and Faulkner 1998) identify (rust, negotiation and cross culture differences in a particular phase of the alliance development. In order to succeed in international coopera- 
tion, organizations need to build and develop trust, to be aware of and overcome the cross culture differences and properly manage the process of negotiation with their partners, not just only during the certain stage of their life but throughout the whole life of their cooperation.

The results of the strategic alliance consultants' research in 1995 (see Ellis 1996) suggest that successful strategic alliance managers are much like diplomats. Unlike line managers, who inust concentrate on immediate profit-and-loss issues. elifective strategic alliance managers make their main focus, bridge building. They act as a shuttle between the new partners, creating relationship. reminding their own tcam to locus on a big picture, and explaining opposing viewpoints. Their role is pivolal particularly in the early phases of the alliance and during a crisis. But the overarching goal of the strategic alliance manager's diplomacy is to create an atmosphere that fosters cooperation for years to come. Trust. negotiation and the awareness of cross culture differences are their key wcapons for this creation. Our next description particularly aims al discussing the process development of these three elements in the span life of strategic alliances. With regard to our framework of stralcgic alliance development above, we can also analyze the development of trust, negotiation and cross culture awareness in three phases: lormation, operation and evaluation.

\section{Trust}

During the engagement of their alliance, in lact partncrs learn about each other motives, capabilitiés, and attitudes lowards conflict, control, cooperation and competition. Trust may decpen as a relationship matures. but this process is hardly alutomalic. Trust must. be nurtured con- tinually because, like a house of cards. trust is hard to build and easy to destroy. After all, trust is person and time dependent. and parties have to make a long-term effort to develop it. No person can be trusted right from the beginning; there is always a possibility ol opportunism. Trust in strategic partnership could be delined as the expectation that the delegates of the other will behave cooperatively (Bocrsma 1999: 46). A qualitative research conducled hy Boersma (1999) shows that trust entails three dimensions:

- promissory-based trust. the expectation that a party can be relied upon to keep a verbal or written promise;

- competence-based trust: the expectation that the other party will perform its role competently;

- goodwill-based trust: the expectation that the other party will take care of the other party's intercst and may be willing to do more than is formally expected.

An unfulfilled expectation on one of those dimensions could decrease or even destroy trust of the other partics, which subsequently has a negative impact on the alliance relationship. Therefore, trust needs io be nurtured during the whole life of stratcgic alliances (Boersma 1999); Nootcboom 1999). Our analysis below discusses how trust develops in each phase of alliances.

In the formation phase, normally the potential partners try to lind information as much as possible about each other (Geringer 1991; Faulknor 1995; Mollering 1997). This is similar to the analogue of marriage. If two people want their marriage to succeed, they olten need to know each other well, before the wedding, disclosing enough information to each other about their real qualities and "the rest." Cooperation at this preparation phase will 
help both partners to strengthen qualities and to overcome weaknesses during their lile together. This is a condition which we call 'courtship phase', as each partner tries (o) get to know each other and tries to build a foundation of trust among them. In reality. however. information about prospective partners will be limited, especially that relating 10 their internal cullures.competence's and values. This means that judgement will have to be made on the basis of the partners' reputations, including those for trustworthiness.

The next step, the operation phase. is a condition when there is a need of mutual understanding to work together. Once the alliance is in the process of implementalion. the people working together from the partner organizations have the opportunity (o know each other more intensively than beforc. The growing ability of each partner's stalf to understand and predict the thinking and actions of the other can provide a further hasis for trust between them. This mutual understanding should reduce the sense of uncertainty that partners experience about each other.

Once the alliance enters the evaluation phase, normally there is also an increasing concern with one another's interest ats well as the growing emotional tics congruence with the over time development of their relationship. In this way. bonding can exist between partners. A virtuous cycle may be established, which reinlorecs both trust and the cooperation that it nurtures. This cycle can, of course be hroken or reversed.

\section{Negotiation}

Negotiation is one of the essential clements in strategic alliances. As Child and Faulkner (1998) stated. a strategic alliance in this respect differs from an accuisition. In particular, acquisitions in- volve the transfer of ownership, which make the acquirer having the right to make any changes in the operations of its new subsidiary that it thinks will fit. constrained only by law and specilic conditions of sale involved in the deal. This condition is not obtained in strategic alliances. Therefore. stratcgic alliance negotiations should bo and are likely to be conducted in a different fashion compared to acquisitions. Far more attention will be given to the fact that the negotiators need to work closely together once the alliance is successfully concluded. Thus. the negotiation in alliance sceks to achieve a relationship between partners that can enable them to achieve business success, without either partner's needing to accept loss of identity or ultimate independence. The negotiation process during each stage of alliance partnership can be depicted as below.

The formation phase has been defined by Mollering (1997) as the "information stage". when the prospective partners try to find out as much as possible about each other. In this phasc, normally cach partner precedes the entry into negotiation on a contract basis. During this initial phase, Lorange (1992) suggests that it is important. from a ncgotiation point of view. to create a clear and easily understood 'win-win situation' for the alliance. which can only be achieved if all parties feel reasonably equal. It is also important that all stakeholders in both organizations endorse the basic joint venture philosophy and approach, explicitly or implicitly. They should develop a clear analytical plan for who does what and when, together with the resource commitments needed. This formation phase has been recognized as an arduous and risky process, as attests the high number of failure of new strategic alliances (Contractor and Lorange 1988). The primary dilficulty resides in finding 
the right partners, agreeing on the methods for running the negotiations, and on the methodological organizations of the steps involved in the negotiation. Therefore. cach party should have an initial strategy, which is dependent on the information attained so far and expectations. The negotiators should list the problems and issucs, especially the conflicting issues and form strategies and choices for all possible solutions they or the other party could suggest. Solutions should be ranked in terms such as preferred, desired, expected and not acceptable. If a solution is not acceptable, a solution that could be acceptable to the other party should then be suggested. It is, thus, important to have several alternative solutions for each problem and issuc (Cavusgil and Ghauri 1990).

The situation in the operation phase is completely different from the former stage. In this phase, the organization of the alliance is developed, high cohesion and interaction occurs. During this situation, normally confrontation, conflict and tension will emerge. Therefore, it is necessary to find ways of resolving the conflicts that are likely to arise in the course of working together. This is also called by Urhan (1996) as a conflict resolution stage for the negotiation area. He discusses two types of conflicts: those that relate to management decisions, and those that relate to the rights and duties of the participating companies, which are the interpretation of the alliance agreement and the assessment of the partner's contribution.

The evaluation phase is a stage where the decision for the continuation of the relationship should be undertaken. In the negotiation process, the parties face a dilemma whether they should dissolve or strengthen their alliunce relationship. If difficulties such as these can be avoided or overcome, and if the alliance proves to be an economic success, then normally the tie of this alliance will be stronger or inight result in a different form such as an acquisition or joint venture. If the relationship is getting worse or the degree of interdependency is weaker, then divorce is the last option they might take. During the cvaluation phase, negotiators face a difficult part for decision-makers to take a wise decision for their company and their alliance relationship. They should be able to gain a benefit for their alliances and make a satisfactory negotiation for both parties.

\section{Cross-Culture Differences}

Many international cooperative relationships fail because of cultural differences. A very large number of companics simply cannot get along with each other. It is not that they do things wrong. It is that they do things differently. Cultural differences affect the way in which the partnership is managed. Differences in approach strain the relationship. Even partners with the best intentions become exasperated. Specific cultural problems are related to miscommunications, human behavioral errors, and clashing management styles. The catch-all phrase is the inability $10 \mathrm{get}$ along. But what are these cultural differences really? How do they manifest themselves? In essence, the complaints centre on the company's cultural style. A company's cultural style is a company's way of doing things, their behaviors and actions (Hall 1995).

This crucial characteristic of culture has been recurrently highlighted by many researchers. who have found empirical support for the notion that a socicty's culture is particularly pervasive across subcultures (Deal and Kennedy 1982; Hofstede 1980; 1991,1993: Morosini 1998). The research done by Hofstede et al. (1990) found that differences in organi- 
zational culture were largely associated with the diversity across the companies' visible practices. However, differences in culture values found within these organizations.were largely attributed to the nationality and demographic characteristic of the employees. Based on the findings of this research. national cultural manifestations are expected to have a pervasive effect on both the nature and the management of an organization's practices, struclure or strategy. which in turn influence performance. As a result, certain cultural values in an organization can also be notoriously difficult to change and adapt. Therefore, in order to be able to manage successlully the cross cultural differences in international strategic alliances both partners need to understand and anticipate the process of cross-cultural adaptation during the whole life of their partnership.

In the formation phase it is important 10 gain awareness of your partner's cullurc. If alliances between organizations that are based on different national cultures are to prove successful -or even get ofl the ground- both parties need first to appreciate and understand the different views and interpretations each other may have on the world. Without this awareness. they cannot even begin to understand more specific behaviors within a corporale context. Comparing differences in management style, reward and decisionmaking processes may tell us 'how' things alc different but withoul a wider contextual understanding of national ideologies and mores, this does not explain 'why' they arc different. Consequently, negative cultural stereotypes are more likely to be reinforced rather than addressed (Cartwright and Cooper 1992). As Trompenaars (1993) observes, people tend automatically to equate something different with something wrong: 'their way is clearly different from ours, so it cannot be right.'

In the operation phase, the sensitivity of cross-cultural differences must also be examined. Managing the alliance culture is a challenge because this stage is about blending and harmonizing two different organizational cultures. Acculturation stress, as in mergers and acquisitions, becomes especially serious for alliances in which one partner plays a dominant role. Whereas in a merger/acquisition it is acceptable for one organizational culture to prevail, in alliances this is rarely so, for partmers in alliances are still independent firms so that both are concerned about losing their own organizational identity in a strategic alliance. Thus, the challenge is to make cultural blending work, while largely preserving the separate cultures. Therefore, managers should be sensitive for cultural differences. A personal adjustment of different cultures will promote better communication between personnel, and improve the effectiveness of teams composed of members from different cultures. In contrast, if these adjustments are lacking, then as a result, the underlying rationale for the alliance may no longer remain valid.

The final stage is the evaluation phase. where we find some partnerships have developed stronger, others have become looser. Related to the culture aspect, there are two possibilities, which might occur during the evaluation phase of international strategic alliances. First, a good acculturation process might provide a new culture for the alliance organization. This is mostly a mixture of the original culture brought by each partner. Second; the mismanagement of culture often causes a breaking of their relationship (Wahyuni and Grotenhuis 2000). 
Figure 3. The Evolution of Trust, Negotiation, and Cross-culture Differences during the Alliance Development

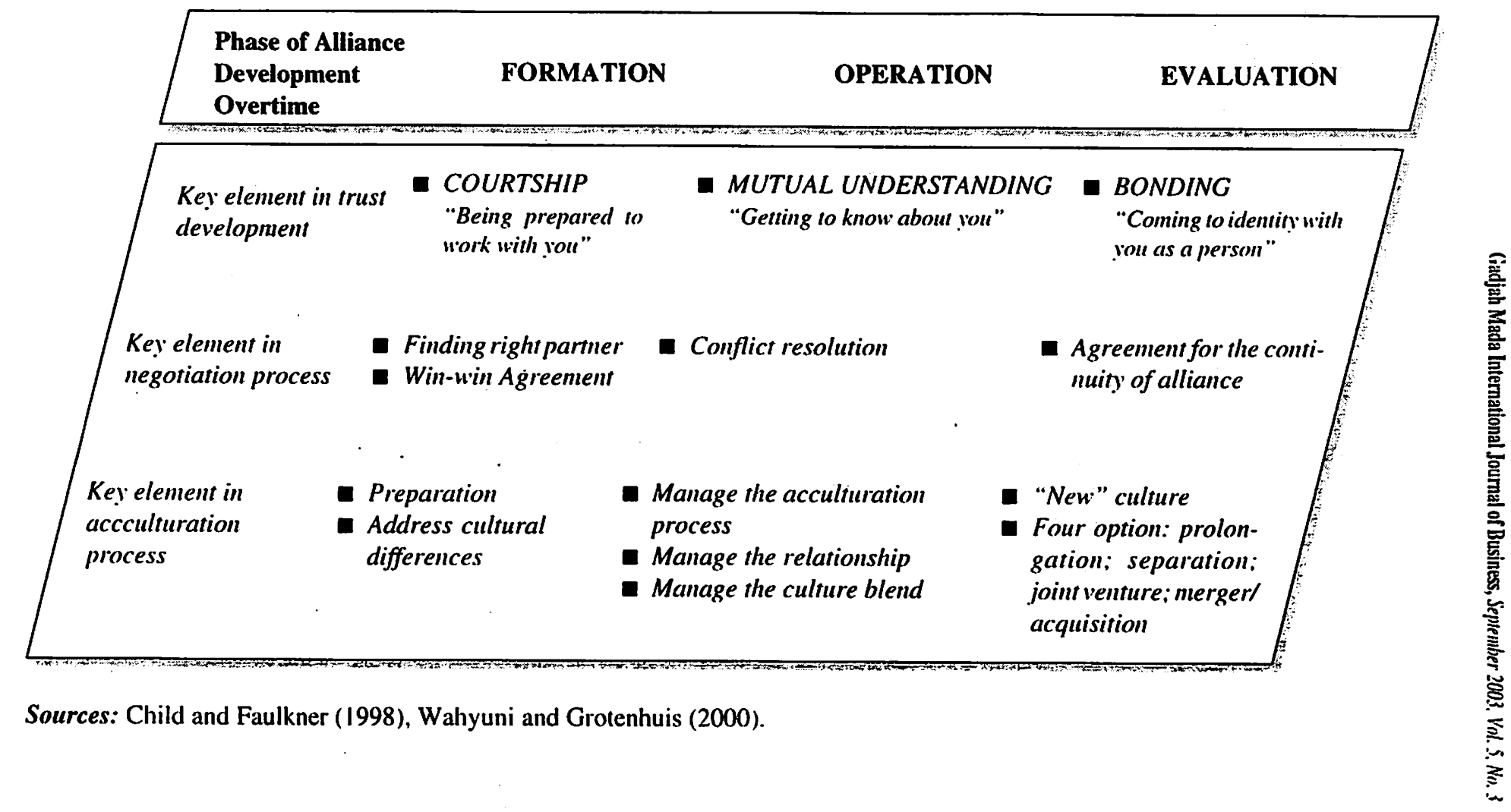


Managers should realize in the beginning that cultural differences might cause failure. because they provide fuel to a downward spiral of misunderstandings, mistrust of intention. conflict and a broken relationship. When cultural dilferences are not managed, misunderstandings occur. This leads to tension in the relationship. The tension increases suspicion of partner intent, and vulnerability is felt more strongly. The higher vulnerability leads partners to be more cautious about cooperating or using their option to withdraw, or delay. Cooperation becomes jeopardized. If cooperation is not being gained. one of the partners is sure eventually to exercise its option to withdraw (Hall 1995).

For a study on how trust, negotiation and cross culture differences could be managed in strategic alliances we refier to Wahyuni (2003) and Wahyuni and Grotenhuis (2000). The summary of the coincidence between trust. negotiation, and cross culture differences within the alliance development can be scen in Figure 3. It should he noted that this framework contains ongoing cycles of adjustments within the diflerent stages.

\section{Conclusion}

This paper has reviewed the extant literature on the process development of strategic alliances from many diflerent perspectives. Each perspective has its own locus. They provide distincl, though sometimes overlapping explanations. Based on our literature survey (Table 1), we come up with our model about strategic alliance development in Figure 2. We divide strategic alliance development into three phases: formation. operation and evaluation. Formation is the phase during which the future partners conceive an interest in the possibility of forming an alliance, un- derstand the motivation, select potential partners, and make the initial agreement in partnercontribution. In the operation phasc. the alliance is established as a productive venture and people are appointed or seconded by the partners, systems installed. operations commenced. Evaluation refers to the ways in which the alliance devclops further following its establishment.

Each phase gives a specific fundament for the alliance to go through the next step of their alliance developinent. It is recognized that the strategic alliances' success is partially the result of the partner selection and the arrangement of clear agrecments during the formation phase of alliances. However, to be able to go through the evaluation phase, the alliance partners should properly manage the operational phase of their alliance. This is what we call as the critical path of alliances when the tension of the conflict might come on the top and the interaction between parties become more intensive. It is not surprisingly that many alliances fail in this phase. Like the marriage metaphor, everything is so exciting and greal in the beginning but after a few years living together we know exactly how our partner is. All bad habils or characters that are not known or shown in the beginning of relationship appear in a natural way. Il we cannot accept and live with it then the marriage bond is in danger. An excellent management of this phase leads to good performance in the alliance cooperation.

This paper endeavors to distill. derive and integrate theories across different perspectives into a unificd franework. which could be applied in every type of alliances. The acknowledgment of the important aspects in each phase of the alliance process is indeed giving a valuable input for alliance managers. A great understanding on the essential aspects and 
the process they might go through will help managers to formulate a proper stratcgy for their international cooperation.

Finally, we believe that the art of strategic alliance management is on how to orchestrate the set of elements and pass every phase of the alliance development successfully. Therefore, it is necessary to sec what kind of factors could assess/ measure those important aspects. Integrating research that attempts to follow alliances over their various life cycle stages and (o) understand better the complex interplay between its business and interper- sonal components will add to the existing knowledge base. We expect that the model that is proposed in this paper provides an avenue for more empirical research in this field. From a manager's point of view this kind of research could also offer practical insights to prevent failures or to reduce obvious mistakes in the development and managcment of (international) strategic alliances. Management might be eager to know how the dynamic elements of their strategic alliances interact and have impact on alliance performance.

\section{References}

Arino. A., and J. de la Torc. 1998. Learning from failure: Towards an evolutionary model of collaborative ventures. Organization Science 9 (3): 306-325.

Beamish. P. W. 1984. Joint venture performance in developing countries. Unpublished Doctoral Dissertation. London: The University of Western Ontario.

Bell. J., and M. F. Boersma. 2000. Eden of troje: Joint ventures vanuit cen strategisch perspectief. Dossier 43 (October).

Bcrquist. W. J. Between, and D. Mevel. 1995. Building Sstrategic Relationship. San Fransisco: Jossey-Bass Publishers.

Blecke, J., and D. Ernst. 1995. Is your strategic alliance really a sale? Harvard Busincess Review 73 (1): 97-105.

Bocrsma. M. F. 1999. Developing trust in international joint ventures. Ph.D. Dissertation. The Netherlands: University of Groningen.

Boyrys. B., and D. Jemison. 1989. Hybrid arrangements as strategic alliances. Acaden!y of Management Rewiew 14: 234-249.

Buchel. B., and P. Killing. 2002. Inter-firm cooperation throughout the joint venture lile cycle: Impact on joint venture performance. In F.J. Contractor, and P. Lorange (eds.): Cooperative strategies and alliances: 751-771. Pcrgamon.

Buchel, B. 2000. Framework of joint ventures development: Theory building through qualitative research. Journal of Management Studies 37: 637-661.

Buchel, B., C. Prange, G. Probst, and Charles C. Ruling. 1998. Intermational Joint Venture Management: Learning to Cooperate and Cooperating to Learn. Singapore: John Wiley and Sons (Asia) Pte Lid. 


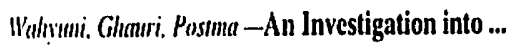

Burgelman, R. 1994. Fading memories: A process theory of strategic business exit in dynamic environments. Administrative Science Quarterly 39: 24-56.

Cameron. K. S., and D. A. Whetten. 1983. Models of the organizational life cycle: Applications to higher education. Review of Higher Education 6. Reprinted in Readings in Organizational Decline: Frameworks, Research, and Prescriptions: 45-62. Edited by K. S. Cameron, R.I. Sutton. and D. A. Whetten. Cambridge. MA: Ballinger (1988).

Cartwright, S., and C.L. Cooper. 1992. Managing Mergers, Acquisitions and Strategic Alliances: Integrating People and Cultures. Butterworth-Heinemann Lid: Oxford.

Cavusgil, S. T. and Ghauri. P. N. 1990. Doing Business in Developing Countries: Enn!y aind Negotiation Strategies. Routledge, London.

Child, J., and D. Faulkner. 1998. Strategies of Cooperation: Managing Alliances. Networks and Joint Venture. Oxford University Press.

Collins. T.. and T. Doorley. 1991. Teaming Up for the 90's. Homewood III.: Irwin.

Contractor. F. J., and P. Lorange. 1988. Cooperative Strategies in International Business: Joint Ventures and Technology Partmerships between Firms. Lexington M.A.

Dacin. M. T., and M. A. Hitt. 1997. Selecting partners for successful international alliances: Examination of U.S. and Korean firms. Journal of World Business 32 (Issue 1): 3-14.

Das. T. K.. and B. S. Teng. 2002. The dynamics of alliance conditions in the alliance development process. Journal of Management Studies 39 (July): 725-746.

Das, T. L.. and N. Rahman. 2002. Opportunism dynamics in strategic alliances. In Cooperative strategies and alliances: 89-117. Edited by F.J. Contractor and P. Lorange. Pergamon.

Deal.T. E., and A. A. Kennedy. 1982. Corporate Culture: Thie Rites and Ritual of Corporate life. Reading, Mass: Addison-Wesley.

Do\%. Y. L. 1996. The evolution of cooperation in strategic alliances: Initial conditions or learning processes? Strategic Management Journal 17 (Summer): 55-85.

Dussauge. P., and B. Garrette. 1998. Anticipating the evolution and outcomes of strategic alliances between rival firms. International Studies in Management chnd Organisations 27 (4): 104-126.

Dussauge. P., B. Garrete., and W. Mitchell. 2000. Learning from competing partners: Outcome and duration of scale and link alliances in Europe, North America and Asia. Strategic Management Journal 21: 99-126.

Dwyer, F. R.. P. H. Schurr. and S.Oh. 1987. Developing buyer-seller relationships. Journal of Marketing 52 (April): 21-34.

Ellis. C. 1996. Making strategic alliance success: The importance of trust. Harvard Business Review 74 (Issue 4): 2-8. 
Faulkner, D. 1995. International Strategic Alliances: Cooperating to Compete. London: McGraw-Hill.

Geringer, J. M. 1991. Strategic determinants of partner selection criteria in international joint ventures. Journal of International Business Studies 22: 41-62.

Geringer, J. M.. and L. Herbert. 1989. Control and performance of international joint venture. Joumal of International Business Studies (Summer): 235-254.

Hall. W. 1995. Managing Cultures: Making Strategic Relationships Work. Wiley: Chichester, UK.

Harbinson, J. R., and P. Pekar Jr. 1998. Sinart Alliances: A Practical Guide to Repeatble Succes. U.S.: Boz Allen and Hamilton.

Holsicde. G. 1993. Cultural constraints in management theorics. Accudemy of Management Executive 7(1): 81-93.

Hofstede, G. 1991. Cultures and Orgamisations: Soffware of the Mind. Maidenhead: McGraw-Hill.

Holstede. G. 1980. Culture's Consequences: International Differences in Woik-Related Values. Beverly Hils, Calif: Sage.

Hyder, S. A. 1988. The Development of International Joint Venture Relationship: A longitudinal Study of Exchange of Resources, Control, Conflict. Upsala: Upsala Reprocentralen. HSC.

Inkpen. A. C., and J. Birkenshaw. 1994. International joint ventures and performance: An inter-organizational. Perspectives, International Business Review 3 (3): 201-217.

Larson. A. 1992. Network dyads in entrepreneurial setting: A study of the governance of exchange relationship. Administrative Science Quarterly 37 (Issue 1): 76-104.

Lei, D., and J. W. Slocum Jr. 1991. Global strategic alliances: Payoffs and pitlalls. Organisational Dynamics: 44-62.

Lorange. P. and J. Roos. 1992. Strategic Alliances: Formation, Implementation and Evolution. Cambridge, Mass: Blackwell.

Lorange. P. 1992. International joint ventures. Financial Times: Handbook of Management.

Mockler, R. J. 1999. Multinational Strategic Alliances. Chichester [etc. |,: John Wilcy.

Mollering, G. 1997. The influence of cultural differences on the establishment of trust hetween partners in international cooperation. Unpublished Paper. Judge Institute of Management Studies, University of Cambridge.

Morosini, P. 1998. Managing Cultural Differences: Effective Strategy and Execution Across Cultures in Global Corporate Alliances. Great Britain: Elsevier Science.

Murray. E. A., and J. F. Mahon. 1993. Strategic alliances: Gateway to the New Europe? Longe Range Planning (26): 102-111. 
Wahrumi. Ghumri, Pusuma-An Investigation into ...

Nooteboom. B. 1999. Inter-firm Alliances: Analysis and Design. London: Routledge.

Pitts. R. A.. and D. Lei. 1997. Building cooperative advantage: Managing strategic alliances to promote organizational learning. Journal of World Business 32 (Issue 3): 203.

Ring, P. S., and A. H. Van de Ven. 1992. Structuring cooperative relationships between organisations. Strategic Management Journal 13: 483-498.

Spekman, R. E., T. M. Forbes III, L. A. Isabella, and T. C. MacAvoy. 1998. Alliance management: A view from the past and a look to the future. Joumal of Mancigement Studies (November): 35-6, November.

Trompenaar. F. 1993. Riding the Waves of Culture: Understanding Cultural Diversity in Business. London: The Economist Books.

Urban. S. 1996. Negotiating international joint ventures. In International Business Negotiation: 231-251. Edited by Pervez N.Ghauri and Jean-Claude Usunier. Britain. Elsevicr Science Lid.

Wahyuni, S. and F. D.J. Grotenhuis. 2000. Developing strategic alliances: The evolution of negotiation, trust, and culture. SOM Paper Competition. The Netherlands: University of Groningen.

Wahyuni. S. 2003. Strategic alliance development: A study on alliances between competing firms. Ph.D. Dissertation. The Netherlands: Ridderprint.

Yoshino, M. Y., and U. S. Rangan. 1995. Strategic Alliances: An Entreprencurial Approach to Globalisation. U.S.A.: Harvard Business School Press. 